\title{
Influencing Student Motivation Through Scaffolded Assignments in a Qual- ity Analysis Course and Its Impact on Learning
}

\section{Dr. Nadiye O. Erdil, University of New Haven}

Nadiye O. Erdil, an assistant professor of industrial and systems engineering and engineering and operations management at the University of New Haven. She has over eleven years of experience in higher education and has held several academic positions including administrative appointments. She has experience in teaching at the undergraduate and the graduate level. In addition to her academic work, Dr. Erdil worked as an engineer in sheet metal manufacturing and pipe fabrication industry for five years. She holds B.S. in Computer Engineering, M.S. in Industrial Engineering. She received her Ph.D. in Industrial and Systems Engineering from Binghamton University (SUNY). Her background and research interests are in quality and productivity improvement using statistical tools, lean methods and use of information technology in operations management. Her work is primarily in manufacturing and healthcare delivery operations. 


\title{
INFLUENCING STUDENT MOTIVATION THROUGH SCAFFOLDED ASSIGNMENTS IN A QUALITY ANALYSIS COURSE AND ITS IMPACT ON LEARNING
}

\begin{abstract}
This paper discusses the impact of various class assignments and activities that build up on each other with the aim of increasing student motivation and student learning in a Quality Analysis course. Scaffolding is an instructional strategy that aims to reduce the amount of cognitive effort that students has to make to learn the materials by breaking down the material into more manageable components. In this study, critical thinking scaffolding is applied in the quality analysis course by structuring several elements to lead students to an assignment that is more complex. At the end of the semester, the impact assessment of critical thinking scaffolding was studied by analyzing student feedback and end-of course surveys, quality of student assignments and course grades.
\end{abstract}

\section{Introduction}

Quality control is one of the primary areas of specialization in Industrial and Systems Engineering (ISE), therefore, a course on quality is typically offered as a core course in the ISE curriculum. Compared to the other ISE specialization areas such as operations research, quality finds applications in all industries and functions, and is employed in all types of sectors including manufacturing, healthcare, entertainment, education, military, and so on. The Lean and Six Sigma methods, that have gained popularity in the last decades, further expand the range of applications of quality. Given the importance of quality in today's world, enhancing student motivation and improving student learning in courses on quality is of significant value in the ISE discipline. With this in focus, this research was conducted to study the following research question: What is the impact of scaffolding of activities on student motivation and learning in a quality analysis course?. This paper discusses the scaffolding strategy implemented to address this question and presents the findings. Scaffolding is an instructional strategy that aims to reduce the amount of cognitive effort that students have to make to learn the materials by breaking down the material into more manageable components.

Instructional scaffolding is based on the Zone of Proximal Development (ZPD) concept introduced by L. Vygotsky. ZPD refers to the range between a person's ability level that is reached by individual efforts and the ability level that can be reached under adult guidance or in collaboration with more capable peers. ${ }^{1}$ Guidance can be provided by helping the learner to focus on particular aspects of the problem by asking leading questions or providing starter information, or simplifying some of the details. ${ }^{2}$

Scaffolding provides a structure that helps students construct knowledge by building new knowledge and competencies upon their existing abilities. It is commonly used in writing and usually given in one the following three forms: 1) breaking up an assignment into smaller assignments, 2) keeping assignment constant but increasing the difficulty of materials, or 3) creating a scaffold within a single assignment. ${ }^{3}$ The levels of learning based on Bloom's Taxonomy can guide the division of the work, in which the components introduced first target 
the lower level outcomes and the latter ones aim at upper levels. This type of scaffolding is known as critical thinking scaffolding ${ }^{4}$ and helps students develop critical thinking skills. In this study, the first approach is tailored and critical thinking scaffolding is applied in a quality analysis course by structuring several elements to lead students to an assignment that is more complex.

Scaffolding has been in use for a long time in academia. Literature presents many successful examples. In a biology class Dirks and Cunningham, using the second approach, applied scaffolding that introduced students to statistical concepts and methods in an increasing complexity through initial exercises and subsequent assignments; they reported that students showed significant gains in their abilities to perform the skills targeted with these assignments. ${ }^{5}$ Linder et al. used a modified version of the first approach and employed scaffolding in redesigning an introductory computer science course to keep students interested in their selected majors and better prepare them for higher-level classes. ${ }^{6}$ Their scaffolding structure included classroom activities and short one-week assignments that target the skills needed in a larger assignment, which was the final class project. They observed that with the instructional scaffolding approach followed in structuring and conducting assignments, the weaker students were able to build skills earlier in the course, and that students showed more confidence in their programming and problem-solving abilities. Browne et al. implemented a critical thinking scaffolding in a recreation management course that is based on case-based learning activities. ${ }^{7}$ The second form of scaffolding was used to guide the case study analysis assignments that increased in complexity throughout the course. They reported positive outcomes in student learning, mainly increased ability in analyzing and formulating recommendations for the case studies reviewed. Boylan-Ashraf et al. conducted a six-year research study involving introductory engineering courses. ${ }^{8}$ One of their research questions was whether scaffolding improves student ability in the next class in their curriculum sequence. They chose the third form of scaffolding approach, and the results showed that scaffolding (and the other methods they studied) have an effect on student performance in the class currently taken and in the following classes. One of the recommendations of the study was to encourage faculty to use scaffolding in their classroom instruction. Girgis used scaffolding for teaching the techniques of problem solving to underrepresented minority students. ${ }^{9}$ Using the second approach, he conducted a oneweek case study in three sessions with increasing complexity, and structured guidance throughout the sessions. His study showed notable progress in students' problem solving skills and received positive feedback from the students.

The approaches in designing assignment scaffolding and the objectives for implementing scaffolding vary, as the previous examples show. But, one thing that is common is that all these studies support that scaffolding has positive impacts on the student outcomes whether this is to improve the ability to perform the targeted skills, to keep students interested in their selected majors, or to improve ability in the next class. The scaffolding presented in this paper targeted to improve students' skills in applying statistical tools in analysis and application of statistical process control and aimed to improve students' critical thinking skills in the process. Critical thinking, as defined by Scriven and Paul, is "the intellectually disciplined process of actively and skillfully conceptualizing, applying, analyzing, synthesizing, and/or evaluating information gathered from or generated by observation, experience, reflection, reasoning, or communication, as a guide to belief and action". 10 In this context, critical thinking targeted in this study is the students' ability to gather information through various activities and connect and integrate this 
information for use (as a guide to action) in a more complex assignment. The approach used is similar to the one employed in Linder et. al. study in terms of assignment sequencing and breaking up a larger assignment into smaller assignments. However, the smaller assignments used in this study are different in nature and type, and how they are connected to each other and to the final assignment. The initial assignments in Linder et. al. study were limited in scope and were short and similar assignments, while this study used assignments of different types and outside class activities. These were structured in a way to encourage and guide students to think about the next assignment while working on the current one and to use their work from the previous assignments in the final assignment.

Research suggests that scaffolding is an effective teaching strategy. In this respect, this paper presents another successful implementation, as the results discussed in the following sections show. Nevertheless, there are not many studies focusing on ISE discipline specific courses. Moreover, in the few that exist scaffolding is not the focus but is discussed as an aiding tool and the details of its implementation are not provided. ${ }^{11,12,13,14}$ This study, therefore, is a valuable contribution to the literature on scaffolding in ISE education, and it provides a framework for ISE education practitioners with the detailed descriptions of the scaffolding strategy implemented, the outcomes targeted, and the assessment used.

\section{Background}

The Quality Course discussed in this study is a graduate level course in the industrial engineering program at the University of New Haven. This course aims to provide fundamental concepts in quality and statistical quality analysis. Topics include principles of quality control systems, control charts for variables and attributes, process capability analysis, measurement system analysis, specification and tolerances, and acceptance sampling plans. Students typically take this course in the second year of their masters program. The course learning outcomes are (a) Define concepts in quality and quality management; (b) Apply statistical tools in analysis and application of Statistical Process Control; (c) Produce and employ control charts; (d) Explain sampling process; and (e) Design acceptance sampling procedures for quality control.

The course work and activities typically include a term paper, a term project, homework, in class exercises and discussions, quizzes and two exams (midterm and final). During the study period the author added the library training and a factory visit to the class activities. A brief definition of each course component is given in Table 1. The relation and relevance of the assignments are explained in the following section.

This is a course that the students associate with their field of study as a primary topic. The previous years' student evaluation results show that students are generally satisfied with the course content, and the author's teaching methods and policies. The survey results from the class period in which this study was conducted provided results similar to the past course evaluation results with average student ratings 4 or above out of 5 . Verifying that the student evaluations were similar to previous years' results allowed eliminating other factors as a source of variation in students rating of the activities linked to the scaffolding structure.

The students were also asked to rate whether they found the level of material covered in the class suitable for the topic and whether they were able to follow this material without being too 
overwhelmed. The evaluation results for these metrics were 4.86 and 4.59 respectively (out of 5). This result also allowed ruling out possible challenges students might have had with respect to the class material as a factor when rating the activities linked to the scaffolding structure.

In the period this study was conducted, only $17 \%$ of the students in the class reported having prior work experience, and 14\% indicated that they are currently working part-time. The remaining students, constituting the majority of the class, did not have any work experience. These numbers are important to show why it is essential to design the class with a focus on practical applications, and structure the assignments with this focus, which we will discuss in more detail below.

Table 1 Learning Outcomes Covered by Each Assignment/Activity

\begin{tabular}{|c|c|c|}
\hline Assignment/Activity & Description & $\begin{array}{l}\text { Targeted Learning } \\
\text { Outcome(s) }\end{array}$ \\
\hline Homework & $\begin{array}{l}\text { Case studies, quantitative problems, conceptual short } \\
\text { answer questions }\end{array}$ & $a, b, c, d, e$, \\
\hline Term Paper & $\begin{array}{l}\text { A literature review study on applications of quality in a } \\
\text { specific industry or field }\end{array}$ & $\mathrm{a}, \mathrm{d}$ \\
\hline Term Project & $\begin{array}{l}\text { Selection of a real life problem and quality tools, } \\
\text { studying the problem using the tools selected, and } \\
\text { reporting findings }\end{array}$ & $\mathrm{b}, \mathrm{c}, \mathrm{e}$ \\
\hline Midterm/Final Exam & In class exams on topics covered in the course & $a, b, c, d, e$, \\
\hline Quizzes & $\begin{array}{l}\text { Take-home assignments or brief } 10 \text {-minute } \\
\text { unannounced quizzes given in class on any topic } \\
\text { covered in lectures }\end{array}$ & $\mathrm{a}, \mathrm{b}, \mathrm{c}, \mathrm{d}$ \\
\hline In class discussions & $\begin{array}{l}\text { Short discussion periods on any course topic steered by } \\
\text { student questions and/or instructor guidance }\end{array}$ & $\mathrm{a}, \mathrm{d}$ \\
\hline In class exercises & $\begin{array}{l}\text { Individual or small group exercises done on computer } \\
\text { during class period }\end{array}$ & $\mathrm{b}, \mathrm{c}, \mathrm{e}$ \\
\hline Library Training & $\begin{array}{l}\text { A single training session on how to use library's } \\
\text { resources for literature search }\end{array}$ & (Indirectly target) a \\
\hline Factory Visit & $\begin{array}{l}\text { A site visit done mid-semester to a manufacturing } \\
\text { company employing many quality control methods }\end{array}$ & (Indirectly target) a \\
\hline
\end{tabular}

\section{Implementation}

The learning outcome that was specifically targeted using scaffolding strategy was to apply statistical tools in analysis and application of Statistical Process Control. The assignments and activities weaved together that contribute to this outcome, either directly or by contributing to a lower level outcome, were library training, term paper, factory visit, and the term project. With project work, students were expected to demonstrate that they could apply quality tools and techniques covered in class to a real-life problem. The library training, the term paper and the factory visit were structured in sequence and the completion of each element was expected to contribute to student motivation and increase their enthusiasm for the project work. Furthermore, these building blocks aimed to provide students the foundational knowledge and understanding of the subject domain, which were essential in conducting the project work. As discussed previously, breaking up an assignment into smaller assignments approach was taken as the starting point for scaffolding, and was tailored for the course such that several elements were put 
in sequence to encourage critical thinking needed for the project work. Figure 1 shows the sequence and relationship between each element.

As students advance from one activity to another, their understanding of the course material should increase both at the cognitive level and at the application level. Working towards the term project assignment, students first needed to acquire an understanding of quality tools, then understand their applications in industry, and finally be able to apply these tools to a real life based problem. The term paper assignment was designed to help students acquire knowledge on relevant topics, and encourage them to draw connections between the material introduced in class and their real life applications. The main learning outcome of this assignment was to demonstrate ability to explain applications of quality tools in real life problems. The factory visit allowed them to observe a system in its real environment and to see the applications of the tools and concepts covered in class.

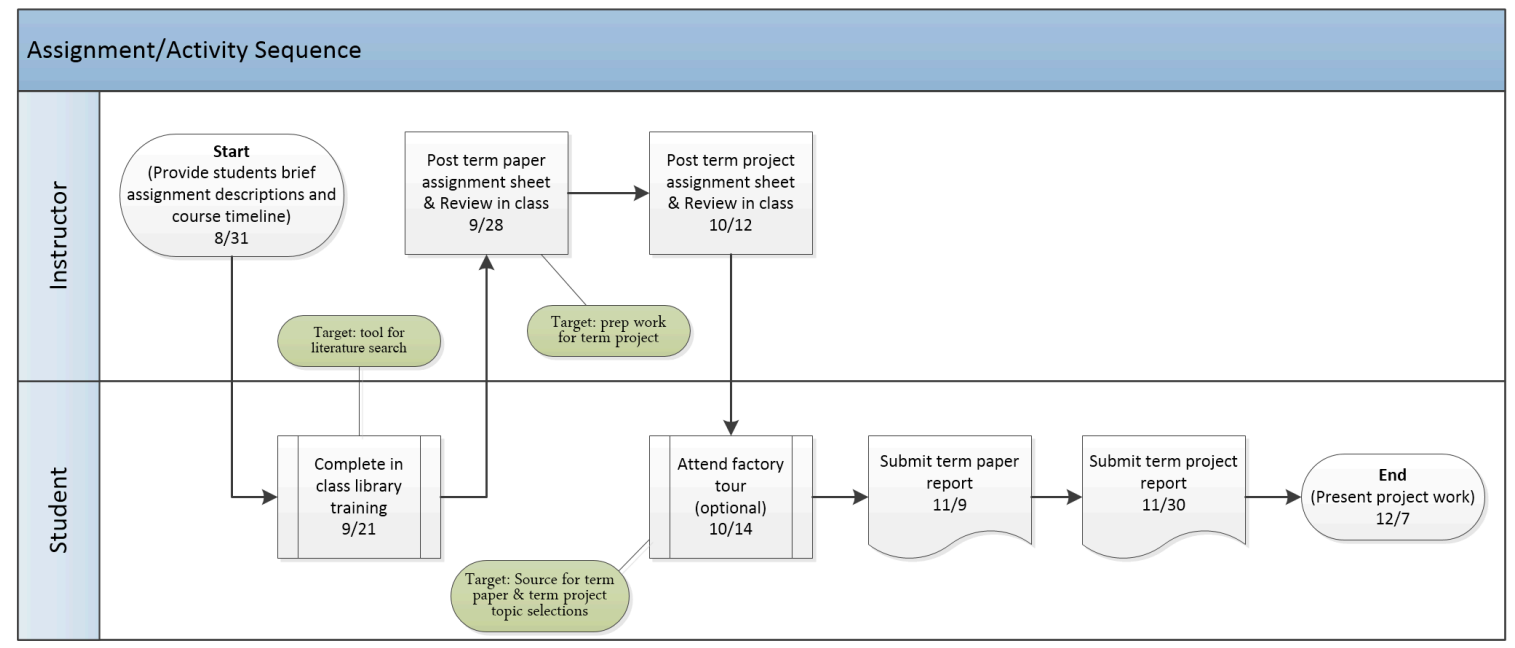

Figure 1 Scaffolding flowchart

It was critical to provide students feedback on each assignment so that they could use their learning from previous assignments. The criteria included in the advice table (shown in Appendix 1) provided the basis for the feedback they received for the term paper. For the factory visit, an in class discussion was held after the visit to provide students a platform to share their observations with each other, and collectively find connections between these observations and their class room learning.

The assignments were timed carefully. The explanations of the assignments and the logic behind their sequence were explained in class in the beginning of the semester, and further explanations were provided during each assignment post date to help students see the connection between each task, and how they can use each assignment to build up knowledge and skills for the next one. Brief descriptions for the assignments are provided below.

\section{Library Training}

The first activity in the sequence was library training. This was an in-class training conducted by the library liaison for engineering. Prior to the training session, the term paper and the term project assignments were discussed in class, and the students were provided the learning 
outcomes targeted with these assignments. The library training was tailored to the topic selected for the term paper assignment and the students were asked to come class prepared with the list of keywords they planed to search for their term paper assignment. The goal with providing students this training was two fold: 1) help them acquire library skills (in general and for use in their term paper assignments) and 2) encourage them to start thinking about topics for their term paper (and possibly term project too) in a timely manner so that they would not leave all work to the last minute.

\section{Factory Visit}

Following the library training, the next activity in the sequence was the factory visit. A plant tour was arranged at a local company manufacturing pins for the telecom, automotive, connector and lighting industries. The company specializes in custom components, and heavily uses statistical quality control methods in monitoring its production. The term paper and the term project assignment sheets were posted in the course learning management system prior to the factory visit. These assignments as well as how the students could benefit from this visit, and the things they should pay attention to and look for while at the manufacturing facility were discussed in class. The factory visit was the only component in the scaffolding structure that was optional to the students.

\section{Term Paper}

In this assignment, the students were asked to study applications of a quality method or tool in a particular industry (e.g. automotive, food, etc.) or field (e.g. manufacturing, healthcare, education, etc.). For their paper, they had to select one industry or field, and one quality method or tool. Based on this pairing, then, they were asked to perform a literature search to find at least two studies presenting applications of the tool chosen in industry/field selected. One of the search requirements was to have at least one of the studies to be a practical application example. The final report included a discussion on the methodology, findings and results of the studies selected as well as the students' learning from these studies. The guideline used to evaluate the term paper report is given in Appendix 1. These guidelines were also provided to the students with the assignment sheet so that they had a clear understanding of how to review and present the studies they found. Table 2 shows the list of topics students chose for this assignment.

Table 2 Term Paper Topics Selected by Students

\begin{tabular}{l|l}
\hline Industry/Field & Quality Tool \\
\hline Education & Control Charts \\
\hline Food Industry & Control Charts \\
\hline \multirow{2}{*}{ Healthcare } & $\begin{array}{l}\text { Control Charts } \\
\text { Measurement System Analysis }\end{array}$ \\
\hline & $\begin{array}{l}\text { Control Charts } \\
\text { Manufacturing }\end{array}$ \\
& $\begin{array}{l}\text { Focess Capability } \\
\text { ANOVA Mode Effects Analysis }\end{array}$ \\
\hline Logistics/Sales & Control Charts \\
\hline
\end{tabular}

\section{Term Project}

The term project assignment is designed to provide students a platform to apply the quality concepts and tools learned in the course. Students were allowed to select their own project topic, 
and the quality tools they would like to use. The projects were conducted in teams of two. Majority of the teams selected control charts as their main tool, while there were a few with process capability analysis; all project topics are listed in Table 3.

Table 3 Term Project Topics

\begin{tabular}{|c|c|c|}
\hline Industry/Field & Method/Tool & Item/Product Studied \\
\hline Economy & Control Charts & Gross Domestic Product \\
\hline Environmental Studies & Control Charts & $\mathrm{CO}_{2}$ monitoring \\
\hline Manufacturing & Control Charts & $\begin{array}{l}\text { Spur gear } \\
\text { Ceramic tiles } \\
\text { Screen mesh } \\
\text { Piston pins }\end{array}$ \\
\hline Manufacturing & $\begin{array}{l}\text { Control Charts \& } \\
\text { Process Capability }\end{array}$ & $\begin{array}{l}\text { Integrated Circuits } \\
\text { Yo-Yo } \\
\text { Airbag sensor pins } \\
\text { Stainless steel pipes }\end{array}$ \\
\hline Service & Control Charts & Service Time \\
\hline
\end{tabular}

\section{Assessment and Findings}

A student survey was used to collect feedback and assess the perceived benefits gained from completing the activities in the structure described above. There were 22 students in class, and all students completed the survey. The students were first asked to identify the course components that enhanced their learning in the context of this class. The results are shown in Figure 2. Although library training received the lowest rating in enhancing student learning, the majority of the students found library training of value (3.95 out of 5) and they thought the training was provided timely in the schedule of course topics and assignments (4.14). In terms of factory visit, the ratings for value and timing were 4.69 and 4.63 respectively.

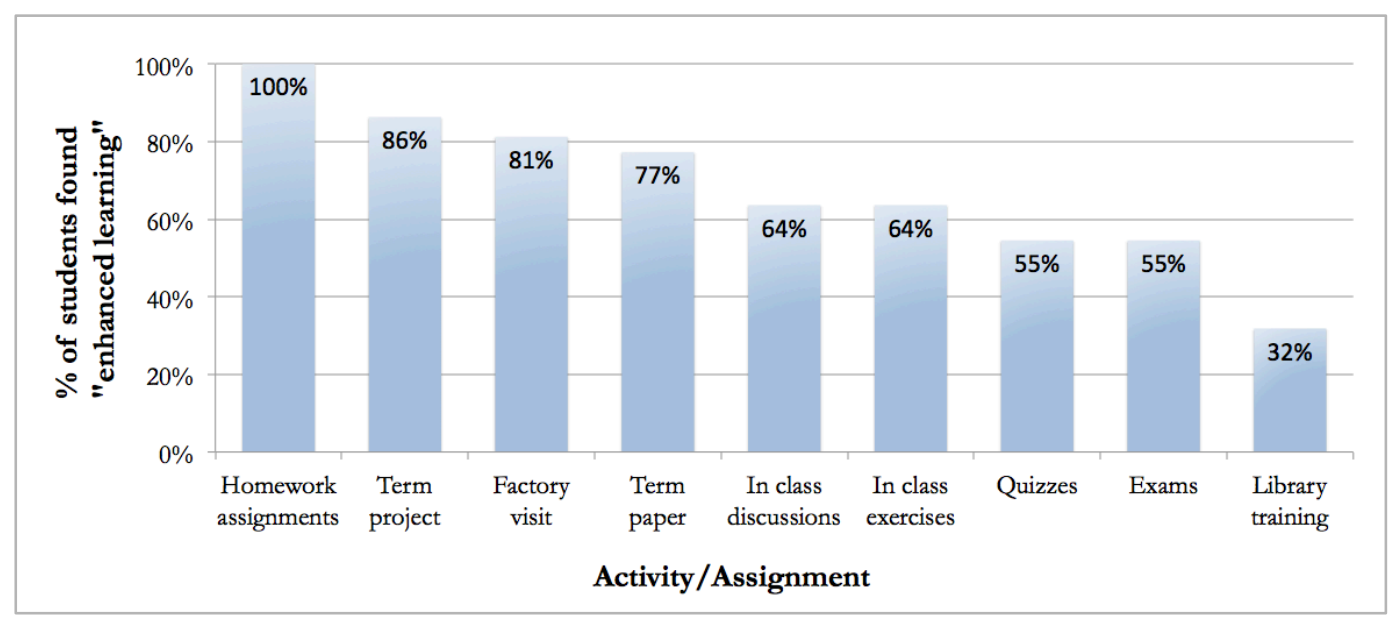

Figure 2 Students Rating of Course Components Contributed Their Learning

The students were then asked to specify their level of agreement on whether any of the first three components in the scaffolded structure had an influence on the following components. Figure 3 shows the percentage of students who indicated that the preceding component in the sequence had an impact on the subsequent components. For example, $90.9 \%$ of the students said that they 
started thinking about possible term project topics while working on the term paper assignment. Similarly, $62.5 \%$ indicated what they learned during the factory visit provided the basis for their term project topic selection. These results imply that the scaffolding structure was effective and support gains in critical thinking, as the majority of the students were able to connect information they obtained from one (or more) activity/assignment to the future assignments.

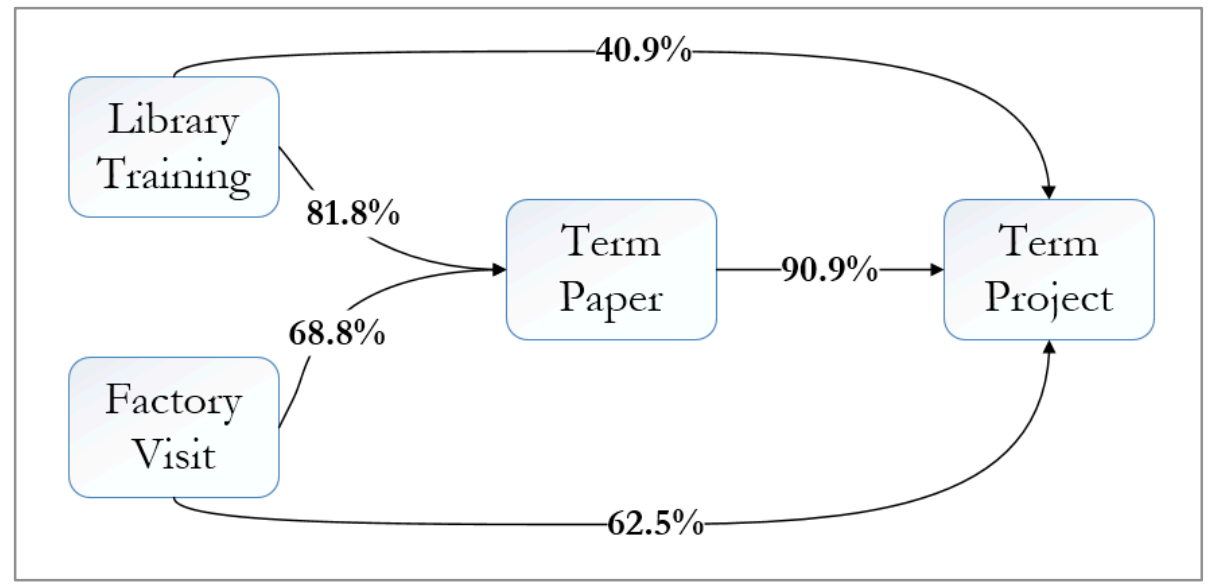

Figure 3 Percentage of students gained benefit from the preceding item

To assess whether the students were able recognize the connection between the term paper and the term project assignments, and use this connection to build up knowledge and material for either assignment, the students were asked to specify if their selection of topics for one assignment influenced the other. The half of the class indicated that they chose their term paper topic based on the topic they planned to work on their term project assignment. About $41 \%$ indicated the other way around, i.e. chose a term project topic based on what they studied for their term paper assignment.

The term project was the final component in the structure, and targeted the higher-level skills in comparison to the previous assignments. All of the students indicated that they understood the purpose of the term project assignment, and $22.7 \%$ reported no challenges in completing the project work. $95.5 \%$ found that the project work allowed them to demonstrate what they learned and that it triggered their curiosity in the context of the class. Nevertheless, $59.1 \%$ reported difficulties in generating a project topic. It appears that more guidance on identifying project topics needs to be provided to the students in the earlier phases of the scaffolding.

Overall, the goal with the scaffolded assignment structure used in this class was to influence student motivation and impact their learning. In addition, the instructor placed emphasis on students' understanding of the relevance of the course topics to real life applications through these scaffolded assignments. Table 4 shows student responses on these targets for each assignment/activity completed. The results indicate that the students strongly agreed that these activities and assignments were effective in accomplishing these goals. The missing data in the table is due to not surveying the students on that metric. The students were also not surveyed on the impact of library training on these goals, as this activity was not directly linked to any of these goals. 
Table 4 Average Student Ratings on Achieving Study Goals

\begin{tabular}{lccc}
\hline The assignment/activity & $\begin{array}{c}\text { Factory } \\
\text { Visit }\end{array}$ & $\begin{array}{c}\text { Term } \\
\text { Paper }\end{array}$ & $\begin{array}{c}\text { Term } \\
\text { Project }\end{array}$ \\
\hline Helped me understand the relevance of the course topics & 4.56 & 4.41 & - \\
\hline Contributed to my learning & 4.50 & 4.32 & 4.86 \\
\hline Enhanced my motivation for the learning in this course & 4.56 & 4.00 & 4.73 \\
\hline
\end{tabular}

Likert Scale: Strongly Agree-5, Agree-4, Neutral-3, Disagree-2, Strongly Disagree-1

The findings on student motivation presented above are very promising. Research suggests that usefulness and relevance of the material, as perceived by the student, are predictors of student motivation. ${ }^{15,16}$ A model on academic motivation, developed by Brett D. Jones, called the MUSIC model, further states that the design of a course plays a significant role in motivating students for learning. ${ }^{16}$ In his model, Jones proposes that the instructors should consider the following five elements to foster student motivation: empowerment, usefulness, success, interest and caring. The scaffolding structure used in this study contains elements that align with those in the MUSIC model. The students were allowed to choose the topics they can study as well as their project partners to empower them; there was en emphasis throughout the scaffolding structure on the explanation of the assignments, their purpose, and relevance to the students' field of study all of which aimed to show students usefulness of the tasks they were asked to complete; assignment rubrics, and timely feedback on each assignment were provided as support for their success, and the fact that scaffolding was used to help students learn the material is a direct contributor to students' success; and the factory visit was included to capture the attention of students to the applications of quality and to trigger their interest. The survey results, presented above, show that these strategies were effective in increasing student motivation, and hence, support the findings of Jones' model on academic motivation. This model furthermore proposes that increased student motivation results in increased student learning. The assessment results from this study on learning, reported below, also support this conclusion.

To assess whether the scaffolding strategy had an impact on student learning, student performance from this study was compared to the previous year's results. The learning outcome targeted was to apply statistical tools in analysis and application of Statistical Process Control. The term project grading rubric used to evaluate the term project assignments is given in Appendix 2. The results in Table 5 show that the student performance was increased on all metrics. The last three metrics in particular, are used to assess student skill at the application level. However, it should be noted that the results presented here are only point averages, and that a larger sample size is required to perform a statistical comparison.

Table 5 Pre and Post Student Performance Comparison

\begin{tabular}{l|cc}
\hline Item & Fall 2016 & Fall 2015 \\
\hline Project Grade - Average (max. 100 pts.) & 73.73 & 70.27 \\
\hline Project Grade - Standard Deviation & 14.77 & 20.99 \\
\hline Project Grade - Minimum & 53.00 & 37.00 \\
\hline Project Component - Analysis Tool Selection (max. 10 pts.) & 7.82 & 7.45 \\
\hline Project Component - Data Analysis (max. 25 pts.) & 16.36 & 14.09 \\
\hline Project Component - Interpretation \& Justification (max. 25 pts.) & 15.91 & 14.09 \\
\hline
\end{tabular}




\section{Conclusion and Future Work}

This paper presents a research study that explored how scaffolding of activities in a quality analysis course affect student motivation and learning and discusses the findings. Critical thinking scaffolding is applied with the goal of increasing student motivation and improving student learning by structuring several elements to lead students to an assignment that is more complex. The study furthermore aimed to influence student understanding of course topics' relevance to real life. The student feedback collected through a class survey showed that the students were able to benefit from the strategy followed by being able to see the connection between the assignments and activities as well as by being able to use one to build up knowledge and skills for the other, which constitutes the scope of critical thinking in the context of this study. The comparison of the student performance in term project work between the term this study was conducted and the previous offering of the course imply that the scaffolding structure was effective in helping students improve their application level skills. Furthermore, the survey results showed that the students found the assignments to enhance their motivation and to contribute to their learning. These results strongly support the hypothesis that scaffolding positively affects student motivation and learning, and that the scaffolding procedure used was effective in accomplishing the goals that were specifically linked to the quality analysis course in this study. The detailed descriptions of the scaffolding strategy and the implementation steps provided here serve as guidelines for ISE education practitioners to support their efforts to implement scaffolding.

Fall 2016 was the first term this scaffolding structure was used in this quality analysis course. The results are very promising, yet, the student feedback identified areas where this structure can be improved to provide further benefits to the students. For example, majority of the students found in class discussions and homework exercises significant in enhancing their learning in this class. Furthermore, they found that these course components also contributed to their performance in producing the work for the term project study. These items can be included in the scaffolding structure explicitly in future implementations, and can be specifically utilized in ways to help students generate a project topic which was a challenge they reported with respect to the project work. Informal and easy to implement active learning activities such as think-pairand share on a topic related to the final assignment could be used to generate discussions in class. For example, when covering measurement system analysis or failure mode effects analysis, the students could be asked to perform a five minute online search to find example applications, then discuss their findings with a partner, and finally share their paired discussion with the entire class. Homework could include scenario-based questions, which could help students link the content to its applications. Another future work would be to apply this scaffolding strategy in other graduate or upper level undergraduate ISE courses. 


\section{Appendix 1: Advice table for the term paper}

\begin{tabular}{ll}
\hline Category & Advice \\
\hline $\begin{array}{l}\text { Problem } \\
\text { Statement }\end{array}$ & Explain the problem (s) introduced in the reference papers clearly and \\
$(20 \%)$ & concisely \\
& List and discuss the question(s) addressed \\
\hline
\end{tabular}

Methodology

$(25 \%)$
- Explain the methodology(s) introduced in the reference papers clearly and concisely
Findings/Results $(20 \%)$

- Discuss findings/results presented in the reference papers
Synthesis

$(20 \%)$
- Using your learning from the previous sections, along with your literature review on the topic you selected, provide a discussion that builds a bridge between the theory and real world practice.

- Structure your paper in a clear, easy to follow format

- Provide complete documentation of your study

- Include data important to your discussion within the text

- Provide references for the source of any information in your work that is not yours

- Select a citation style, and use this style for all your references

- Provide your paper in one document prepared using word processor software

Written Report

$(15 \%)$
- Visual Displays (tables, graphs, etc.):

○ Use clear headings to identify purpose

○ Label the plot (meaningful title, properly labeled axis including units)

- Include meaningful and easy to understand legend if needed

- Include captions that are explanatory of information presented (table caption starts the word "Table" followed by table number; figure caption starts with "Figure" followed by figure number)

- Refer to your display in the text with its caption 
Appendix 2: Advice table for the term project

\begin{tabular}{|c|c|c|c|c|c|c|c|}
\hline 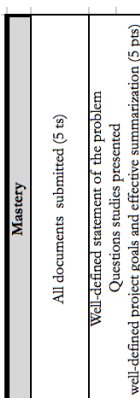 & 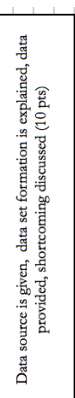 & 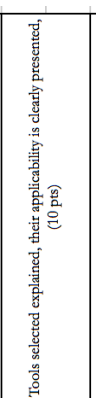 & 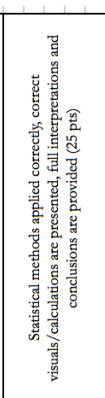 & 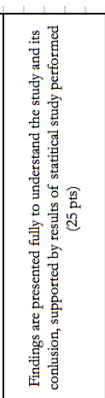 & 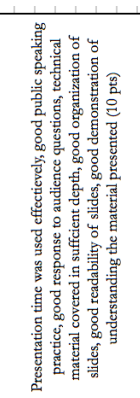 & 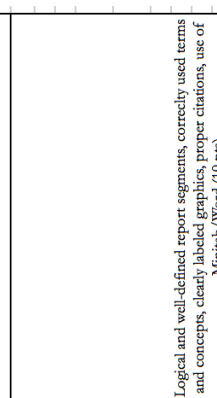 & \\
\hline 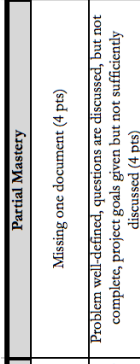 & 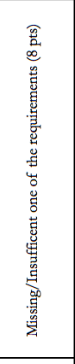 & 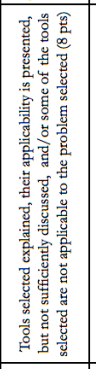 & 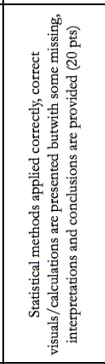 & 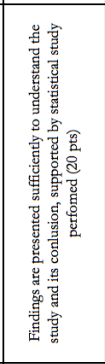 & 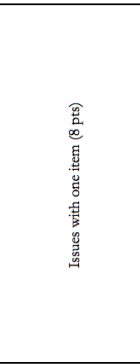 & 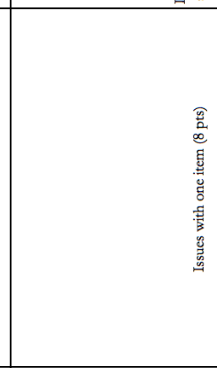 & \\
\hline 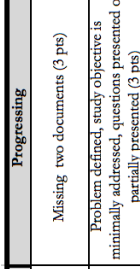 & 童量要 & 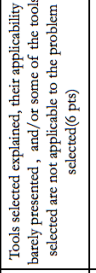 & 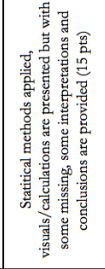 & 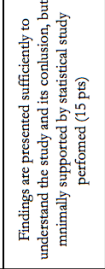 & 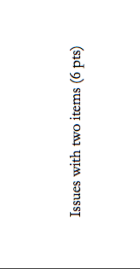 & & \\
\hline 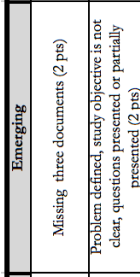 & 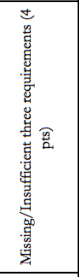 & 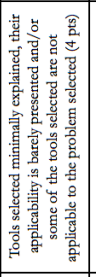 & 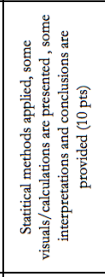 & 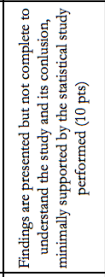 & & 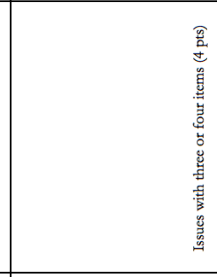 & \\
\hline 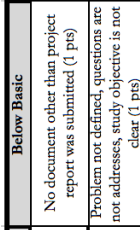 & 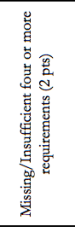 & 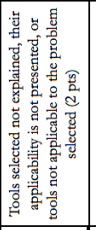 & 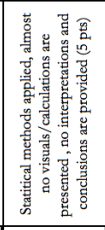 & & 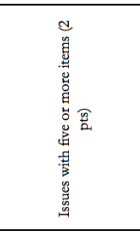 & & \\
\hline 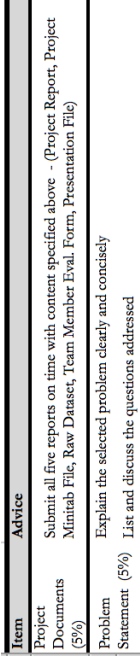 & 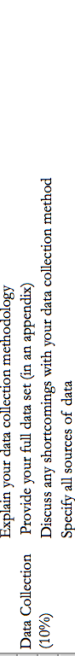 & 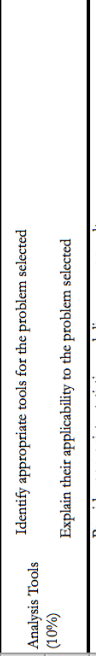 & 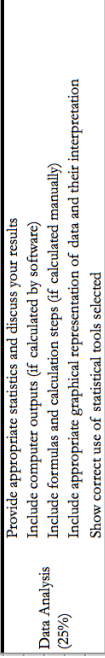 & 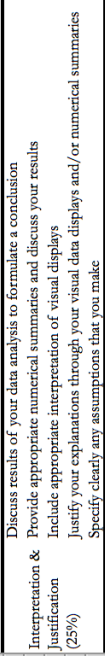 & 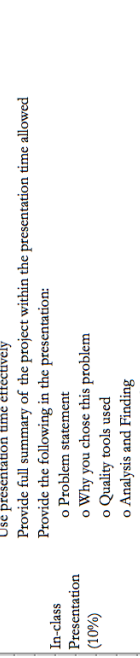 & 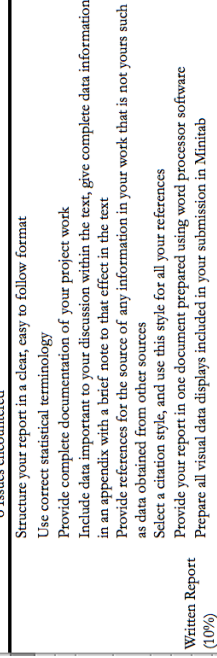 & 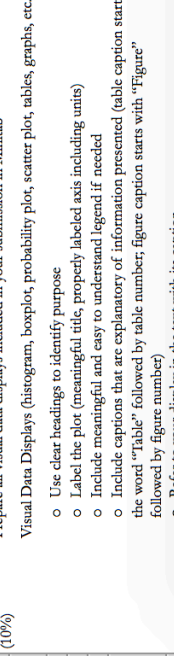 \\
\hline
\end{tabular}




\section{References}

1. Vygotskii, L.S. and Cole, M. (1978). "Mind in society: The development of higher psychological processes." Cambridge: Harvard University Press.

2. Putnam, C., O’Donnell, J., \& Bertozzi, N. (2010). Scaffolding and fading within and across a six-semester CDIO design sequence. Proceedings. International Conceive Design Implement Operate (CDIO) Conference.

3. Schroeder, C. (2011-2012). "Scaffolded Assignments: Designing Structure and Support". Retrieved from http://www.hartnell.org/sites/default/files/llark/designingscaffoldedassignmentsbooklet_1_.pdf

4. Skene, A. and Fedeko, S. (n.d.). "Assignment Scaffolding”. Retrieved from https://ctl.utsc.utoronto.ca/technology/sites/default/files/scaffolding.pdf

5. Dirks, C. and Cunningham, M. (2006). "Enhancing diversity in science: is teaching science process skills the answer?". CBE Life Sci. Educ., 5:218-226.

6. Linder S., Abbott D., and Fromberger, M. (2006) "An Instructional Scaffolding Approach to Teaching Software Design”. Journal of Computing Sciences in Colleges, 21(6): 238-250.

7. Browne, L., Hough, M., and Schwab, K. (2009). "Scaffolding: A promising Approach to Fostering Critical Thinking”. Schole: A Journal of Leisure Studies \& Recreation Education. 24: 114-119.

8. Boylan-Ashraf, P., Freeman, S., Shelly, M. (2015). "Scaffolding in Introductory Engineering Courses". Journal of STEM Education, 16(4):6-12.

9. Girgis, M. (2015). "A Scaffolding Case Study for Teaching Engineering Problem Solving to Underrepresented Minorities". Proceedings. American Society of Engineering Education Conference.

10. Kellogg, S. (2007). “Technology Enabled Support Modules for Engineering Management”. Proceedings. American Society of Engineering Education Conference.

11. Scriven, M., and Paul, R., (1987). "Critical Thinking as Defined by the National Council for Excellence in Critical Thinking". Retrieved from http://www.criticalthinking.org/pages/defining-critical-thinking/766

12. Jaksic, C. and Spencer, D. (2009). "A Manufacturing Processes Laboratory: What BookMaking and Sheet-Metal Working Have in Common”. Proceedings. American Society of Engineering Education Conference.

13. Kim, KY., Psenka, C.E., Jackson, K.S., and Haapala, K.R., (2015). "Constructionist Learning for Environmentally Responsible Product Design”. Proceedings. American Society of Engineering Education Conference.

14. Kellogg, S. (2005). "Scaffolding, Learning styles, and Web-Based Tutorials". Proceedings. American Society of Engineering Education Conference.

15. Wigfield, A., and Eccles, J. S. (2000). Expectancy-value theory of achievement motivation. Contemporary educational psychology, 25(1), 68-81.

16. Jones, B. D. (2009). Motivating Students to Engage in Learning: The MUSIC Model of Academic Motivation. International Journal of Teaching and Learning in Higher Education, 21(2), 272-285. 